\title{
A STUDY ON THE COUPLING RELATIONSHIP BETWEEN BASIC PUBLIC SERVICES AND MULTI-DIMENSIONAL POVERTY IN RURAL POOR AREAS EMPIRICAL ANALYSIS BASED ON HECHI CITY, GUANGXI
}

\author{
Wan Yuan ${ }^{1}$, Wang Yanhui ${ }^{1, *}$, Gong Zhaoning ${ }^{1}$,Duan Fuzhou ${ }^{1}$, Deng Lei ${ }^{1}$ \\ 1. College of Resources Environment \& Tourism, Capital Normal University, Beijing 100048, China.
}

Commission III-IVc: Environment and Health

KEY WORDS:Rural basic public services,Multidimensional poverty,Coupling relationship,Evaluation criterion,poverty
reduction,GIS

\begin{abstract}
:
With the orderly promotion of the national poverty alleviation work, the number of rural poor people in China has decreased significantly, but due to the imbalance of regional development, deep poverty areas still exist. The balanced development of rural basic public services(RBPS) is one of the important directions to solve the deep-seated contradictions in poor areas. In this paper, Hechi City of Guangxi Province is taken as the research area, and the multi-dimensional poverty measurement model and RBPS evaluation model are constructed respectively. The collaborative development relationship between RBPS and multi-dimensional poverty reduction in the research area is revealed by coupling coordination degree and GIS spatial analysis method. The results show that the spatial distribution of coupling degree and coupling coordination degree between basic public services and multi-dimensional poverty is unbalanced. Basic public services and multi-dimensional poverty are closely related, and the level of basic public services has a positive impact on multi-dimensional poverty, and the poverty reduction of basic public services is feasible. In order to achieve stable and sustainable poverty eradication, it is necessary to establish a scientific and systematic evaluation system of rural basic public service poverty reduction.
\end{abstract}

\section{INTRODUCTION}

Poverty is a global problem, which has existed for a long time. In 2011, the State Council issued and implemented the outline of China's rural poverty alleviation and development (2011-2020) (hereinafter referred to as the "new outline") which proposed the balanced development level of rural basic public services as the core indicator of poverty alleviation effectiveness monitoring in poverty-stricken counties in the next decade(Chi et al, 2016).In 2018, the State Council issued the strategic plan for Rural Revitalization (2018-2022). It pointed out that we should strengthen the construction of rural infrastructure to ensure and improve the people's livelihood in rural areas, enhance the supply of rural public services, and strengthen services from public grassroots services, pension services and other aspects. At the Fourth Plenary Session of the 19th Central Committee of the Communist Party of China in 2019, it was proposed that the national basic public service system should be improved.It includes education, education, income from work, medical care for the sick, support for the elderly, housing, support for the weak, etc. Therefore, to explore the coupling relationship between basic public services and multi-dimensional poverty in povertystricken areas has a profound impact on poverty alleviation, rural revitalization, improving people's livelihood and building a welloff society in an all-round way.

Since the advent of AF algorithm(Alkire and Foster, 2007) in Oxford University in 2007, international research on Multidimensional Poverty Measurement and empirical research began to rise. In China, the research on multi-dimensional poverty started late. The early research is a small amount of theoretical research, and the later research mostly uses the existing data to verify the research area. Some of these studies explore the relationship between basic public services and poverty reduction.

Some scholars (Chi and Wang, 2016b) selected 67 poverty alleviation key counties in Wuling Mountain's contiguous poverty-stricken areas to build an evaluation index system of RBPS in poverty-stricken areas. Some scholars (Wang et al, 2018) integrated Tapio model and weighted Voronoi circle structure to reveal the relationship between basic public services and county economy in China's poor areas in 2010-2012. Some scholars (Hao et al, 2019) found that basic public services have poverty reduction benefits for rural multi-dimensional poverty, and the poverty reduction effects of compulsory education and health care, which play a leading role in the "empowerment" mechanism, are greater. Based on China's provincial panel data from 2004 to 2015 , the impact of basic public services on the urban-rural income gap was empirically studied by using the system generalized moment method (sys-gmm)( Liu et al, 2019). In terms of theory, Wang Yu(Wang and Wang, 2018) have theoretical concepts, practical concerns and evaluation suggestions on poverty reduction of basic public services. Internationally, Rhys Andrews and Steve Martin (2010) analyzed the impact of policy differences on public services in England, Scotland and Wales, and compared the effectiveness indicators of urgency, basic medical services, education, social services, welfare, waste management, and community safety to find the regional differences in public services. Domingues AR (2015) based on the theory of sustainability, constructed 36 indicators to evaluate the sustainability of local government public services from three aspects: environmental protection, economic development, ethics and social responsibility .

To sum up, scholars at home and abroad have studied basic public services and poverty from different perspectives, but there are few researches on the coupling relationship between basic public services and multi-dimensional poverty. In this paper,

\footnotetext{
* Wang Yanhui - wangyanhui77@126.com
} 
from the perspective of RBPS and multi-dimensional poverty, the coupling characteristics of RBPS and multi-dimensional poverty are analyzed in space and with reference to the coupling coordination model The formation mechanism analysis serves for targeted poverty alleviation and rural revitalization, and promotes the development of basic public service poverty alleviation.

\section{STUDY AREA AND DATA RESOURCE}

\subsection{Study Area}

As shown in Figure 1, Hechi City belongs to Guangxi Zhuang Autonomous Region, which is located between $106^{\circ} 34^{\prime} \sim 109^{\circ}$ $09^{\prime} \mathrm{E}$ and $23^{\circ} 41^{\prime} \sim 25^{\circ} 37^{\prime} \mathrm{N}$. It is located in the northwest border of Guangxi and the south foot of Yunnan Guizhou Plateau It is $228 \mathrm{~km}$ long from east to west, $260 \mathrm{~km}$ wide from south to north, with a total area of $33500 \mathrm{~km}^{2}$ and a total population of 4.5 million. Guangxi Zhuang Autonomous Region is one of the most populated areas of ethnic minorities. Hechi City is mainly mountainous area, with high terrain in the northwest and low terrain in the southeast. The mountains are mostly distributed in the marginal areas. The terrain is diverse and karst is widely distributed. The area of rocky desertification land is 722600 hectares, which is a serious area of karst terrain fragmentation and rocky desertification in China. As a part of the 14 national key poverty alleviation areas, the rocky desertification area of Yunnan, Guangxi and Guizhou is an underdeveloped area integrating "the old, the few, the border, the mountain, the poor and the reservoir". It is also a key area for Guangxi to implement the western development.

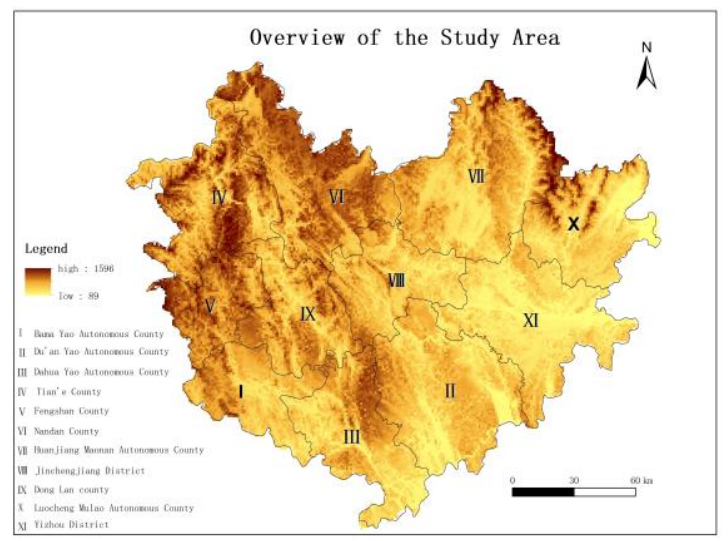

Figure 1. Overview of the study area

\subsection{Date Resource and preprocessing}

The data of this study includes socio-economic data and basic geographic data. The social and economic data mainly come from the special data, economic statistical yearbook and field survey data of 2013 rural social and economic development statistics and monitoring of Hechi Poverty Alleviation Office, including public service information such as education, health care, culture and social security on the county statistical scale; the basic geographic data mainly include 1:250000 basic geographic data of the research area. Before using, all data should be preprocessed, social and economic data should be screened, unreasonable data should be eliminated and normalized; geospatial data should be processed by projection coordinate registration and clipping. The method of data standardization is Max-min.

\section{METHODS}

\subsection{Evaluation model of rural basic public service}

Bertot (Bertot et al , 2016) believes that public services include water, food, energy, income security, health services and other necessary public goods and services (Sen, 1985). Wang $\mathrm{Yu}$ (Wang et al, 2018)defined basic public service as a public service that is led by the government, ensures the basic needs of all citizens' survival and development, and adapts to the level of economic and social development. In this paper, basic public services generally include education services, employment services, social security services, public health services, family planning services, housing security services, cultural and sports services and other areas of public services to ensure the basic needs of people's livelihood(Chi and Wang , 2016). According to the principles of scientificalness, integrity and operability, the evaluation model is constructed in combination with the research of existing scholars' index systems(Chi and Wang, 2016; Hao et al, 2019).

3.1.1 Composition of basic public service evaluation index system:The establishment of the index system not only includes the most basic public services in the poverty-stricken areas on the county scale, but also the basic services provided by the government to the public for agricultural production and farmers' life. In the process of data processing, the indexes whose complex correlation coefficient is greater than 0.6 are eliminated, and the requirements of index characterization and consistency are met. The weight determination adopts the subjective and objective weight reorganization method which combines AHP and entropy method. This method not only makes up for the strong subjectivity of AHP, but also satisfies the researchers' preference for indicators. At the same time, it optimizes the combination of the two methods based on the game theory. See Table 1 for specific descriptive information.

3.1.2 Calculation model of rural basic public service: The commonly used comprehensive evaluation methods of RBPS include AHP, TOPSIS, multivariate statistical analysis, grey system evaluation and comprehensive index. According to the data information, this paper chooses the comprehensive index method to represent the development level of RBPS in each county. The RBPS formula is as follows:

$$
R B P S_{i}=\sum_{j=1}^{n} x_{i j} w_{j} \quad(1)
$$

Where $X_{\mathrm{ij}}$ is the $\mathrm{jth}$ rural basic public service index measurement value of County i after standardization; $\mathrm{W}_{\mathrm{j}}$ is the weight value of the $\mathrm{jth}$ index; $\mathrm{n}$ is the number of basic indexes, where $\mathrm{n}=$ $21 ; \mathrm{RBPS}_{\mathrm{i}}$ is the comprehensive index of rural basic public service in County $\mathrm{i}$, and the comprehensive index of rural basic public service in each region / Province is the average value of the 5 comprehensive indexes of the counties under its jurisdiction. The larger the comprehensive index is, the better the overall development of basic public services in the region is. The smaller the comprehensive index is, the worse the overall development of basic public services in the region is.

\subsection{Multidimensional Poverty Measurement Model}

3.2.1 Construction of Multidimensional Poverty Index System:This paper based on the principles of whether the indicators are scientific, typical and easy to obtain, relevance and operability with local policies in order to more accurately reflect the poverty situation in the study area. It refers to the indicator system(Andrews and Martin, 2010;Cao et al, 2016) proposed by 
various researchers and removes the indicators related to the basic rural public service indicators. Then this paper established a poverty index for the established indicators Poverty identification standard (deprivation line), and the establishment of Hechi county-level multi-dimensional poverty measurement index system shown in Table 2, a total of 5 dimensions, 11 basic indicators. So that the abstract multi-dimensional poverty measurement can be transformed into a specific measurement index system.

In the process of data processing, AHP and entropy method continue to be used. The contribution of each dimension to multidimensional poverty is the same, and the dimension weight is the same. The contribution of indicator weight in each dimension is also considered the same.

3.2.2 The construction of Multidimensional Poverty Measurement Model:At present, the A-F double critical value method proposed by Alkire and foster (2011) is unanimously recognized internationally to calculate the Multidimensional Poverty Index. In this paper, the subjective analytic hierarchy process (AHP) and objective entropy weight method are used to weight each index respectively, and the final weight of each index is obtained by using the combination weight method based on Game Theory (Wang and Chen, 2018). This combination weighting method can not only satisfy the decision-maker's subjective preference, but also take into account the information law of the data itself. On this basis, the calculation method of MPI can be summarized into three steps: the recognition of single dimension poverty; the recognition of multi dimension deprivation; the summation of dimensions, as follows:

(1)Identification of single dimension poverty

Based on the dimensions and indicators in Table 1, the observation matrix $\mathrm{X}$ is established with the user as the research unit:

$$
\mathrm{X}=\left(\begin{array}{ccc}
X_{11} & \ldots & X_{1 d} \\
\ldots & X_{i j} & \ldots \\
X_{n 1} & \ldots & X_{n d}
\end{array}\right)(2)
$$

Each row in the matrix represents the information of a household, and each column represents a dimension, so $X_{i j}$ represents the status of the $\mathrm{j}$-th dimension of the $\mathrm{i}$-th household, $i=1,2, \ldots, n, j=1,2, \ldots, d$ 。

Let $Z_{j}\left(Z_{j}>0\right)$ be the critical value of poverty, that is, the poverty line. Transformation of matrix $X$ to deprivation matrix $g^{0}$ by $Z_{j}$.

$$
g^{0}=\left(\begin{array}{ccc}
g_{11}^{0} & \ldots & g_{1 d}^{0} \\
\ldots & g_{i j}^{0} & \ldots \\
g_{n 1}^{0} & \ldots & g_{n d}^{0}
\end{array}\right)(3)
$$

If $X_{i j}>Z_{j}$, the value of $g_{i j}^{0}$ is 0 , indicating that the $\mathrm{j}$ dimension of the $\mathrm{i}$-th household is not deprived; if $X_{i j}\left\langle Z_{j}\right.$, the value of $g_{i j}^{0}$ is 1 , indicating that the $\mathrm{j}$ dimension of the $\mathrm{i}$-th household is deprived.

(2) Recognition of multidimensional deprivation

The critical value of deprivation $(\mathrm{k})$ is the critical value to judge whether a farmer belongs to multidimensional poverty 。 On the basis of the deprivation matrix $g^{0}$, count and sum the deprivation situation of each peasant household to $h_{i}$. if $h_{i}>\mathrm{k}$, then peasant household I is a multi-dimensional poor household, otherwise it is not a multi-dimensional poor household. Finally get the adjusted deprivation matrix $g^{0}(\mathrm{k})$

$$
g^{0}(\mathrm{k})=\left(\begin{array}{ccc}
g_{11}^{0}(k) & \ldots & g_{1 d}^{0}(k) \\
\ldots & g_{i j}^{0}(k) & \ldots \\
g_{n 1}^{0}(k) & \ldots & g_{n d}^{0}(k)
\end{array}\right)(4)
$$

(3) Sum of dimensions

The incidence of Multidimensional Poverty is defined as $\mathrm{H}$, so:

$$
\mathrm{H}=\mathrm{q} / \mathrm{n}(5)
$$

$\mathrm{q}$ is the number of multi-dimensional poor households. $\mathrm{n}$ is the total number of households in the region (village level).

The average deprivation share is defined as A, so:

$$
\mathrm{A}=\frac{\sum_{i=1}^{n} c_{i}(k)}{q}=\frac{\sum_{i=1}^{n} c_{i}(k)}{d q}
$$

Thus, the MPI of each village can be obtained:

$$
\mathrm{MPI}=\mathrm{H} \times \mathrm{A} \quad \text { (7) }
$$

\subsection{Coupling analysis of rural basic public service and multi dimension poverty}

Coupling model refers to the phenomenon that two (or more) systems or motion forms interact with each other through various interactions. This concept originated from physics . In this paper, the coupling degree between the two is calculated by the way of standardized ranking, and the calculation formula is as follows:

$$
\mathrm{C}=\left(\frac{U_{1} * U_{2}}{\left[\alpha * U_{1}+\beta U_{2}\right]^{2}}\right)^{n}(8)
$$

Among them, $\mathrm{C}$ is the coupling degree of rural basic public service and multi-dimensional poverty; $U_{1}$ is the multidimensional poverty value ranking, and the larger $U_{1}$ is the lower level of poverty; $U_{2}$ is the comprehensive index ranking of rural basic public service, and the larger $U_{2}$ is the lower level of rural basic public service; $\mathrm{n}$ is the coordination coefficient, taking $\mathrm{n}=$ 3 to increase the differentiation.

The value range of $\mathrm{C}$ is 0 to 1 . When $\mathrm{C}=1$, the coupling degree is the largest, and when $\mathrm{C}=0$, the coupling degree is the smallest. As an important indicator to reflect the coupling degree of RBPS and multi-dimensional poverty in Hechi City, the coupling degree plays an important role in judging the coupling degree between systems in a specific time and space, but it is difficult to reflect the overall coordination degree between regional basic public services and multi-dimensional poverty. Therefore, it is necessary to build RBPS and multi-dimensional poverty The model of coupling coordination degree:

Calculation formula of coupling co scheduling (D):

$$
\mathrm{D}=\sqrt{C * P}(9)
$$

Among them, calculate the comprehensive evaluation index (P)(Li andWang,2016) :

$$
\mathrm{P}=\alpha * U_{1}(X)+\beta * U_{2}(X)(10)
$$

Among them, $\mathrm{D}$ is coupling co scheduling; $\mathrm{C}$ is coupling degree; $\mathrm{P}$ is comprehensive score.

Among them, $\alpha$ and $\beta$ are undetermined coefficients. In this study, RBPS and multi-dimensional poverty are considered equally important, so the values are all 0.5 .

Based on the research results of relevant scholars(Cao et al, 2016; Niu and Wang, 2017), and according to the actual situation and research needs of the research area, the coupling degree and coupling coordination degree are divided into three categories by using the natural breakpoint method: low degree, medium degree and high degree coupling; declining maladjustment type, endangered maladjustment type and coordinated development type.

Finally, according to the development differences of basic public service index and multi-dimensional poverty index, the coupling coordination degree of the study area is divided into four types ( $\mathrm{Li}$ andWang, 2016; Cao et al, 2016; Niu and Wang, 2017)(Table 3), $U_{1}$ is the multi-dimensional poverty value ranking; $U_{2}$ is the comprehensive index ranking of rural basic public service.

\begin{tabular}{cc}
\hline Classification & Coordinated difference type \\
\hline $0<\mathrm{U} 1 / \mathrm{U} 2 \leq 0.5$ & $\begin{array}{c}\text { Types of serious lag in basic } \\
\text { public services } \\
\text { Types of slight lag in basic } \\
\text { public services }\end{array}$ \\
\hline
\end{tabular}




\begin{tabular}{cc}
\hline $\mathrm{U} 1 / \mathrm{U} 2=1$ & Type of synchronization \\
$1<\mathrm{U} 1 / \mathrm{U} 2 \leq 3$ & $\begin{array}{c}\text { The types of mild lag in } \\
\text { Multidimensional Poverty } \\
\text { Types of serious lag in } \\
\text { Multidimensional Poverty }\end{array}$ \\
\hline
\end{tabular}

Table 3. Classification criteria of coupling coordinated difference types

\section{RESULT ANALYSIS}

\subsection{Multidimensional Poverty and general situation of basic public services in the study area}

In arcgis10.6 software, output the evaluation index of countylevel RBPS and multi-dimensional poverty comprehensive index(MPI) of Hechi City into a map.Then get the spatial distribution map of the two indexes as shown in Figure 2.

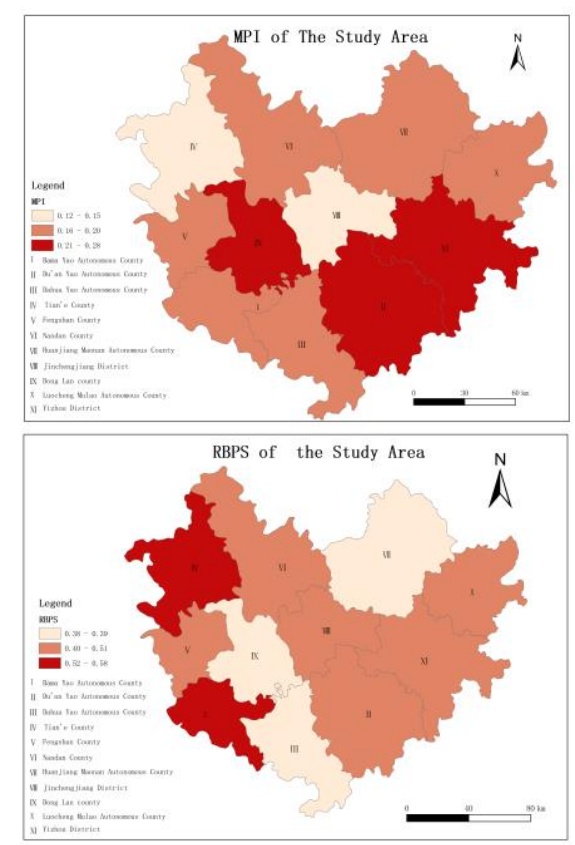

Figure 2. Spatial distribution of MPI and RBPS in the study area

It can be seen from Figure 2 that the overall situation of county-level multi-dimensional poverty in Hechi City is characterized by small dispersion and large concentration. Donglan County, Du'an Yao Autonomous County and Yizhou district have the deepest degree of multi-dimensional poverty, which is concentrated in the south of the area around Jinchengjiang. The causes of multi-dimensional poverty are complex. Although the altitude of these areas is relatively low, but the vegetation coverage is low .It belongs to the topography of half mountain and half hill. The high population density leads to traffic congestion, poor living conditions, relatively few education and medical facilities, and the high incidence of multidimensional poverty. The incidence of Multidimensional Poverty in Tian'e county and Jinchengjiang district is relatively low. As the former political and economic center of Hechi City, Jinchengjiang district has a relatively low incidence of multidimensional poverty. It has the only airport in the city, convenient transportation, and complete educational and medical facilities. In addition, the multi-dimensional poverty situation of Tian'e county is also weak. Because the terrain of the area changes
greatly.And it also has high average altitude,high vegetation coverage, and small population density .

The basic public services in rural areas of the study area are distributed in "small scattered and large strip". The overall level of basic public services in Tian'e county and Bama Yao Autonomous County in the west developed well. The terrain of the area is fluctuant, the forest coverage is high, the population density is small, and the ecological environment protection is good. In the central part of Donglan County, Dahua Yao Autonomous County and Huanjiang Maonan Autonomous County, the overall level of basic public services is relatively poor. The karst landform area accounts for a large proportion, the land is severely rocky desertification, the forest coverage is low, the population density is large, and the demand for public service resources is large.

\subsection{The coupling analysis of RBPS and MPI}

4.2.1 Analysis of the whole related characteristics: This paper analyzes the close relationship and dependence between basic public services and multi-dimensional poverty in rural areas through the coupling model. Based on the coupling analysis of 11 districts and counties in the study area, this paper obtains the coupling relationship, coupling coordination degree and coupling coordination difference relationship between RBPS and multidimensional poverty, as shown in Figure 3 and table 4:
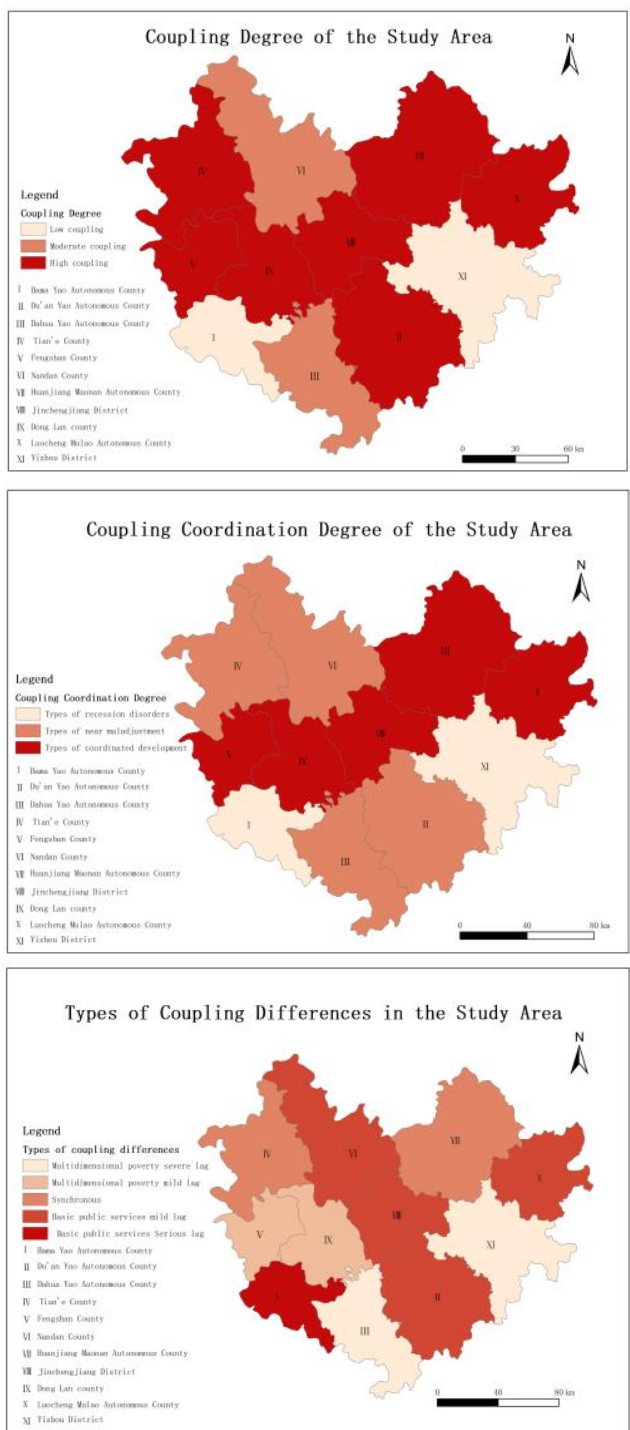
Figure 3. Coupling degree, coupling coordination degree and coupling coordination difference between basic public services and multi-dimensional poverty in rural areas of the study area

From Figure 3, it can be seen that the coupling degree and coupling coordination degree of Hechi City appear axis watershed distribution. The coupling degree between Yizhou district and Bama Yao Autonomous Region is low, and the coupling degree between Nandan county and Dahua Yao Autonomous County is moderate, which is distributed on both sides of the east-west axis. The counties on the axis are highly coupled. The coupling coordination degree forms a coordinated development axis from southwest to northeast. Tian'e County, Nandan county, Dahua Yao Autonomous County and Du'an Yao Autonomous County on both sides of the axis are on the verge of maladjustment. Yizhou district and Bama Yao Autonomous County on the south of the axis are on the verge of maladjustment. The coupling difference type shows the distribution characteristics of "whole scattered, local gathered".

4.2.2 Analysis of coupling degree characteristics: 7 counties show high coupling degree in Hechi City.Among them, the karst landform in Huanjiang Maonan Autonomous County is significant, the basic public service facilities are few, and the incidence of multi-dimensional poverty is low. The forest coverage rate of Tian'e County reaches $82.6 \%$, and the degree of land desertification and rock desertification is low, so the incidence of multi-dimensional poverty is relatively low. Jinchengjiang district is located in the central area of Hechi, which is a hilly area with low altitude, relatively flat terrain, sufficient sunshine, mild climate, abundant rainfall and large population density. At the same time, it has obvious advantages in administrative village location as a municipal district. There is little gap between the development of basic public services and economic conditions in the above regions.

Nandan county and Dahua Yao Autonomous County present medium coupling degree. The influence of terrain factors is serious in Dahua Yao Autonomous County and Nandan county The vegetation coverage is high, the degree of land desertification and stone desertification is relatively low, and the basic public service level and economic development are in the middle position in Hechi City.

Yizhou district and Bama Yao Autonomous County show low coupling degree. There is a big gap between the comprehensive index of multi-dimensional poverty and the index of basic public services in Yizhou district. Under the influence of topography and geomorphology factors, the vegetation coverage rate of Yizhou is low, and it belongs to the topography of half mountain and half hill, the net yield of vegetation is low, the per capita net income of farmers is low, and the rural infrastructure is poor. The overall level of basic public services in Bama Yao Autonomous County is developing well. The terrain fluctuates greatly, the forest coverage rate is high, the population density is small, and the economic development is seriously behind the basic public service level.

4.2.3 Analysis of the characteristics of coupling coordination degree :Hechi City is on the verge of maladjusted and declining maladjusted areas and counties, which are mainly distributed in the southeast and south of the study area. The effect of basic public services on poverty reduction is not obvious.

The coordinated development type of districts and counties are concentrated on the axis from northeast to southwest, and the basic public services are positively related to the multidimensional poverty level, which complement and restrict each other. These areas are relatively consistent in terrain, low forest coverage and relatively large population density. By improving the level of basic public services, we can effectively improve the effect of multi-dimensional poverty reduction.

Through the coupling difference type, we can see that the basic public service and economic level of Tian'e county and Huanjiang Maonan autonomous county develop synchronously and harmoniously. The economic development level of Bama Yao Autonomous Region and other counties lags behind the development level of basic public services, especially Bama Yao Autonomous Region and Nandan county. The coupling degree between them is low, and the development of coupling coordination degree is declining. The gap between economic development and basic public service level is large. Therefore, we should increase economic development. The development level of basic public services in Donglan County et al lags behind the economic development, especially in Yizhou district. Yizhou district is now the new administrative center of Hechi City, with low forest coverage and high population density. In the future, the economic development speed will increase, the population density will increase, and the development speed of basic public services will be higher. In the future, we should vigorously develop basic public services such as science, education, culture and health.

\section{CONCLUSION}

This paper constructs the evaluation system of rural basic public service and multi-dimensional poverty in Hechi City. By calculating the coupling degree, coupling co scheduling and dividing the coupling difference types, it systematically and comprehensively reveals the coordinated development relationship between basic public service and multi-dimensional poverty in the study area. 11 counties in the study area were studied.

The situation of multi-dimensional poverty shows an increasing trend from northwest to Southeast, and multidimensional poverty areas and counties show a spatial distribution pattern of "large dispersion and small aggregation"; while the situation of basic public services is low in the West and high in the East, the development level of the North-South border is good. Districts and counties with low coupling degree and poor coupling coordination degree focus on the fact that economic development lags behind the development level of public services, which is mainly due to the disjointed development of the two, resulting in poor coupling and complex multidimensional poverty situation. In the area of coordinated development, there is a strong positive correlation between the level of basic public service and the degree of Multidimensional Poverty in each region. The level of basic public service and Multidimensional Poverty complement and restrict each other. In the unbalanced area, there is a significant negative correlation between the basic public service and the multi-dimensional poverty, which indicates that the improvement of the basic public service level and the development of multi-dimensional poverty reduction are not synchronous.

In the future, our goal is to alleviate relative poverty, which requires us to build a balanced development mechanism of basic public services and increase the security of basic public services. At the last moment of the battle to get rid of poverty, we should make up for the shortcomings and lay a solid foundation. In order to promote the effect of basic public services on poverty reduction in poverty-stricken areas, we should establish a scientific and comprehensive evaluation system for poverty reduction of basic public services, include poverty reduction of basic public services in the multi-dimensional poverty reduction system, and formulate effective government policies. 


\section{REFERENCES}

Alkire S,Foster J.Counting and multidimensional poverty measurement[J].Journal of Public Economics, 2007, 95( 7) :476487.

Andrews R,Martin S. Regional variations in public service outcomes:the impact of policy divergence in England, Scotlandand Wales[J].Regional Studies,2010,44(8):919-934.

Bertot J,Esteveze E,Janowski T. Universal and contextualized public services:Digital public service innovation framework [J]. Government Information Quarterly ,2016,33(2):211-222.

Cao SS., Wang YH.,Duan FZ,et al. Coupling between ecological vulnerability and economic poverty in contiguous destitute areas, China: Empirical analysis of 714 poverty stricken counties[J]. Chinese Journal of Applied Ecology,2016,27(08):2614-2622.

Chi Y., Wang YH., Fang N.. Spatio-temporal pattern of rural basic public services and county economy in poverty-stricken contiguous destitute areas of China[J]. geographical research, 2016, 35(7): 1243-1258.

Domingues A R,Pires S M,Caeiro S,et al.Defining criteria and indicators for a sustainability label of local public services[J]. Ecological Indicators,2015,57:452-464.
Hao XW.,Huang NB.,Zhuang Y.. Research on the Effect of Public Service on Rural Multidimensional Poverty Reduction in the Perspective of Rural Revitalization[J].China Soft Science, 2019(01):72-81.

Liu, HT., He, QY. The effect of basic public service on urbanrural income inequality: a sys-GMM approach[J]. Ekonomska Istrazivanja-Economic Research,32(1),3205-3223

Niu YQ., Wang SL..Research of the coupling relationship between the vulnerable ecological environment and povey in Gansu Province[J].Aeta Ecologica Sinica,2017,37(19):64316439.

Sen A. A sociological approach to the measurement of poverty:A reply to Professor Peter Townsend[J].Oxford Economic Paper, 1985,37(4):669-676.

Wang Y., Wang SG.. Poverty reduction in basic public services: theoretical concepts,practical concerns and evaluation suggestions [J]. Guizhou Social Sciences,2018 (09): 164-168

Wang, Y. H., Chi, Y. Measuring spatiotemporal changes of rural basic public service in poverty-stricken area of China. International Regional Science Review, 41(5), 510-539.

APPENDIX

\begin{tabular}{|c|c|c|c|c|c|c|c|c|}
\hline Dimension & Indicator & unit & $\begin{array}{l}\text { Complex } \\
\text { correlation } \\
\text { before } \\
\text { elimination } \\
\end{array}$ & $\begin{array}{l}\text { Retained } \\
\quad \text { or } \\
\operatorname{not}(\mathrm{Y} / \mathrm{N})\end{array}$ & $\begin{array}{l}\text { Complex } \\
\text { correlation } \\
\text { after } \\
\text { elimination } \\
\end{array}$ & $\begin{array}{l}\text { Subject } \\
\text { weight }\end{array}$ & $\begin{array}{l}\text { Objective } \\
\text { weight }\end{array}$ & $\begin{array}{c}\text { Combined } \\
\text { weight }\end{array}$ \\
\hline \multirow{3}{*}{$\begin{array}{l}\text { Rural } \\
\text { fundamental } \\
\text { education }\end{array}$} & $\begin{array}{l}\text { Ratio of } \\
\text { administrative } \\
\text { villages having one or } \\
\text { more kindergartens or } \\
\text { preschools }\end{array}$ & $\%$ & 0.435 & $\mathrm{Y}$ & 0.425 & 0.118 & 0.065 & 0.100 \\
\hline & $\begin{array}{l}\text { Ratio of preschool } \\
\text { children able to get } \\
\text { access to kindergarten }\end{array}$ & $\%$ & 0.567 & $\mathrm{Y}$ & 0.550 & 0.237 & 0.042 & 0.126 \\
\hline & $\begin{array}{l}\text { Ratio of } 15 \text { - to } 18- \\
\text { year-old children } \\
\text { enrolling in senior } \\
\text { high school }\end{array}$ & $\%$ & 0.660 & $\mathrm{~N}$ & & & & \\
\hline \multirow{4}{*}{$\begin{array}{l}\text { Rural } \\
\text { environment } \\
\text { protection }\end{array}$} & Forest coverage ratio & $\%$ & 0.539 & $\mathrm{Y}$ & 0.516 & 0.044 & 0.044 & 0.054 \\
\hline & $\begin{array}{l}\text { Ratio of } \\
\text { administrative } \\
\text { villages having one or } \\
\text { more rubbish } \\
\text { recycling } \\
\text { depots }\end{array}$ & $\%$ & 0.563 & $\mathrm{Y}$ & 0.541 & 0.009 & 0.069 & 0.061 \\
\hline & $\begin{array}{l}\text { Ratio of } \\
\text { administrative } \\
\text { villages having one or } \\
\text { more landfill sites }\end{array}$ & $\%$ & 0.525 & Y & 0.493 & 0.009 & 0.040 & 0.037 \\
\hline & $\begin{array}{l}\text { Ratio of } \\
\text { administrative } \\
\text { villages having one or } \\
\text { more full-time } \\
\text { cleaners }\end{array}$ & $\%$ & 0.687 & $\mathrm{~N}$ & & & & \\
\hline \multirow[t]{2}{*}{$\begin{array}{l}\text { Rural public } \\
\text { safety }\end{array}$} & $\begin{array}{l}\text { Ratio of } \\
\text { administrative } \\
\text { villages having one or } \\
\text { more police service } \\
\text { rooms }\end{array}$ & $\%$ & 0.512 & $\mathrm{Y}$ & 0.486 & 0.031 & 0.097 & 0.093 \\
\hline & $\begin{array}{l}\text { Ratio of } \\
\text { administrative }\end{array}$ & $\%$ & 0.502 & Y & 0.497 & 0.031 & 0.091 & 0.088 \\
\hline
\end{tabular}




\begin{tabular}{|c|c|c|c|c|c|c|c|c|}
\hline & $\begin{array}{l}\text { villages having one or } \\
\text { more community } \\
\text { policemen }\end{array}$ & & & & & & & \\
\hline \multirow{2}{*}{$\begin{array}{l}\text { Rural public } \\
\text { health }\end{array}$} & $\begin{array}{l}\text { Ratio of } \\
\text { administrative } \\
\text { villages having clinics }\end{array}$ & $\%$ & 0.440 & $\mathrm{Y}$ & 0.423 & 0.031 & 0.033 & 0.040 \\
\hline & $\begin{array}{l}\text { Number of hospital } \\
\text { beds per thousand } \\
\text { people }\end{array}$ & & 0.498 & $\mathrm{Y}$ & 0.478 & 0.031 & 0.003 & 0.014 \\
\hline \multirow{4}{*}{$\begin{array}{l}\text { Rural social } \\
\text { security }\end{array}$} & $\begin{array}{l}\text { Number of Social } \\
\text { Welfare Institutes' } \\
\text { beds per thousand } \\
\text { people }\end{array}$ & & 0.523 & $\mathrm{Y}$ & 0.503 & 0.020 & 0.008 & 0.014 \\
\hline & $\begin{array}{l}\text { Ratio of per thousand } \\
\text { people enrolling in the } \\
\text { New Rural } \\
\text { Cooperative } \\
\text { Medical Insurance of } \\
\text { China }\end{array}$ & & 0.338 & $\mathrm{Y}$ & 0.301 & 0.100 & 0.010 & 0.047 \\
\hline & $\begin{array}{l}\text { Ratio of per thousand } \\
\text { people enrolling in } \\
\text { rural social } \\
\text { endowment insurance } \\
\text { Ratio of } \\
\text { administrative } \\
\text { villages having one or } \\
\text { more community } \\
\text { service centers }\end{array}$ & $\%$ & 0.288 & $\mathrm{Y}$ & 0.254 & 0.100 & 0.044 & 0.076 \\
\hline & $\begin{array}{l}\text { Ratio of } \\
\text { administrative } \\
\text { villages having fund } \\
\text { mutual cooperative }\end{array}$ & $\%$ & 0.635 & $\mathrm{~N}$ & & & & \\
\hline \multirow{4}{*}{$\begin{array}{l}\text { Rural public } \\
\text { culture }\end{array}$} & $\begin{array}{l}\text { Ratio of } \\
\text { administrative } \\
\text { villages having one or } \\
\text { more sport/culture } \\
\text { squares }\end{array}$ & $\%$ & 0.582 & $\mathrm{Y}$ & 0.468 & 0.006 & 0.057 & 0.049 \\
\hline & $\begin{array}{l}\text { Ratio of } \\
\text { administrative } \\
\text { villages having fitness } \\
\text { equipment }\end{array}$ & $\%$ & 0.636 & $\mathrm{~N}$ & & & & \\
\hline & $\begin{array}{l}\text { Ratio of } \\
\text { administrative } \\
\text { villages having access } \\
\text { to radio and television }\end{array}$ & $\%$ & 0.541 & $\mathrm{Y}$ & 0.531 & 0.028 & 0.019 & 0.027 \\
\hline & $\begin{array}{l}\text { Ratio of } \\
\text { administrative } \\
\text { villages having access } \\
\text { to broadband network }\end{array}$ & $\%$ & 0.583 & $\mathrm{Y}$ & 0.568 & 0.028 & 0.068 & 0.067 \\
\hline \multirow{6}{*}{$\begin{array}{l}\text { Rural } \\
\text { infrastructure } \\
\text { economic }\end{array}$} & $\begin{array}{l}\text { Ratio of } \\
\text { administrative } \\
\text { villages having access } \\
\text { to cement/asphalt road }\end{array}$ & $\%$ & 0.574 & $\mathrm{Y}$ & 0.553 & 0.075 & 0.058 & 0.078 \\
\hline & $\begin{array}{l}\text { Ratio of } \\
\text { administrative } \\
\text { villages having access } \\
\text { to electricity }\end{array}$ & $\%$ & 0.560 & $\mathrm{Y}$ & 0.556 & 0.032 & 0.015 & 0.025 \\
\hline & $\begin{array}{l}\text { Ratio of } \\
\text { administrative } \\
\text { villages having access } \\
\text { to passenger bus }\end{array}$ & $\%$ & 0.542 & $\mathrm{Y}$ & 0.517 & 0.014 & 0.059 & 0.055 \\
\hline & $\begin{array}{l}\text { Ratio of } \\
\text { administrative } \\
\text { villages having access } \\
\text { to safe drinking water }\end{array}$ & $\%$ & 0.468 & $\mathrm{Y}$ & 0.456 & 0.032 & 0.057 & 0.060 \\
\hline & $\begin{array}{l}\text { Ratio of } \\
\text { administrative } \\
\text { villages having } \\
\text { agricultural } \\
\text { greenhouse facilities }\end{array}$ & $\%$ & 0.660 & $\mathrm{~N}$ & & & & \\
\hline & $\begin{array}{l}\text { Ratio of } \\
\text { administrative }\end{array}$ & $\%$ & 0.442 & $\mathrm{Y}$ & 0.375 & 0.007 & 0.059 & 0.052 \\
\hline
\end{tabular}


villages having

livestock facilities

Table 1. Evaluation index weight of RBPS in Hechi City

\begin{tabular}{|c|c|c|c|c|c|}
\hline Dimension & $\begin{array}{l}\text { Dimension's } \\
\text { weight }\end{array}$ & Indicator & Poverty identification standard & $\begin{array}{l}\text { Indicator's } \\
\text { weight }\end{array}$ & Combined weight \\
\hline Income & $1 / 5$ & $\begin{array}{l}\text { Per capita net income } \\
\text { of farmers }\end{array}$ & $\begin{array}{l}\text { Per capita net income is less than the } \\
\text { national poverty line ( } 2300 \text { yuan) }\end{array}$ & $1 / 5$ & 1.000 \\
\hline \multirow[t]{2}{*}{ Medical health } & $1 / 5$ & $\begin{array}{l}\text { The healyh status of } \\
\text { farmers }\end{array}$ & $\begin{array}{l}\text { Some members of the family are not } \\
\text { healthy }\end{array}$ & $1 / 10$ & 0.6 \\
\hline & & $\begin{array}{l}\text { Medical Insurance } \\
\text { offarmaers }\end{array}$ & $\begin{array}{l}\text { Some family members do not have } \\
\text { medical insurance }\end{array}$ & $1 / 10$ & 0.4 \\
\hline \multirow[t]{2}{*}{ Education } & $1 / 5$ & Adult illiteracy rate & $\begin{array}{l}\text { Illiterate or semi illiterate adults in the } \\
\text { family }\end{array}$ & $1 / 10$ & 0.652 \\
\hline & & Child dropout rate & $\begin{array}{l}\text { 6-16-year-old school-age children drop } \\
\text { out of school (nine-year compulsory } \\
\text { education) }\end{array}$ & $1 / 10$ & 0.348 \\
\hline \multirow[t]{5}{*}{ Standard of living } & $1 / 5$ & $\begin{array}{l}\text { Difficulties in } \\
\text { drinking water }\end{array}$ & $\begin{array}{l}\text { No water pipes or independent wells in } \\
\text { the farmer's home }\end{array}$ & $1 / 25$ & 0.133 \\
\hline & & Unsafe drinking water & $\begin{array}{l}\text { Farmer's drinking water is not shallow, } \\
\text { deep or tap water }\end{array}$ & $1 / 25$ & 0.139 \\
\hline & & Health facilities & $\begin{array}{l}\text { There is no toilet or flush toilet in the } \\
\text { farmer's house }\end{array}$ & $1 / 25$ & 0.172 \\
\hline & & Fuel type & $\begin{array}{l}\text { Farmers use firewood, straw and other } \\
\text { non clean fuels }\end{array}$ & $1 / 25$ & 0.263 \\
\hline & & Housing situation & $\begin{array}{l}\text { The houses of farmers are non brick } \\
\text { wood and reinforced concrete } \\
\text { structures }\end{array}$ & $1 / 25$ & 0.293 \\
\hline Social security & $1 / 5$ & Social insurance & $\begin{array}{l}\text { Members of the family do not have any } \\
\text { social insurance (endowment } \\
\text { insurance, unemployment insurance, } \\
\text { etc.) }\end{array}$ & $1 / 5$ & 1.000 \\
\hline
\end{tabular}

Table 2. Multidimensional poverty measurement index and their corresponding weights 